\title{
Design and Intervention of an Educational-Leadership Program: Student Voice and Agency, Expectations and Internationalization
}

\author{
Anna Elizabeth du Plessis ${ }^{1}$ \\ ${ }^{1}$ Learning Sciences Institute Australia, Australia \\ Correspondence: Anna Elizabeth du Plessis, 229 Elizabeth Street, Brisbane, CBD, Qld, Australia. Tel: \\ 61-44-887-9496 \\ Received: January 7, 2017 \\ Accepted: January 27, 2017 \\ Online Published: February 14, 2017 \\ doi:10.5430/ijhe.v6n1p251 \\ URL: http://dx.doi.org/10.5430/ijhe.v6n1p251
}

\begin{abstract}
This paper explores the lived experiences of a diverse student cohort enrolled in a master's degree educational-leadership program. The program's global focus was on the quality of teacher education, prospective teachers' workplace preparedness and leaders in the workforce in higher education. Internationalization, real-life experiences and student voice served as an enacted intervention curriculum for an educational leadership course designed to reveal the gap between theory and practice. An epistemological diversity lens stimulated critical reflection on students' participation in the course design and its connection to realities in the field. Diverse higher-education classrooms pose specific challenges for educational leadership programs in including effective internationalization, workplace relevance and improving the generalizability and content validity of the educational leadership course. This small qualitative exploratory investigation provides an in-depth understanding of the value of student voice in informing course and program design. Interviews, observations, two surveys and a document analysis triangulated the data and provided information on the complexities in higher-education classrooms. The findings focus on teacher-educators and higher-education classroom management as well as on the value of critical inquiry, reflection and intervention for existing course designs and transformation.
\end{abstract}

Keywords: Quality higher education, Student voice, Internationalization, Educational-leadership, Workplace readiness, Teacher preparation, Gap between theory and practice, Teacher-educator agency

\section{Introduction}

Higher-education teacher programs are expected to provide student-teachers and leaders with quality preparation that sets them up for success (Teacher Education Ministerial Advisory Group [TEMAG], 2014), and develops skills that will benefit the teaching workforce and advance the workplace. Luke, Luke, and Mayer (2000) claim that teacher education can be perceived as a discipline, social field, profession, knowledge or expertise and reflective practice.

The purpose of this study is to investigate the effectiveness of a master's degree educational-leadership program, designed to prepare postgraduate students for leadership in order to develop an intervention program according to the needs of a diverse student cohort. This paper describes the design of an intervention program that was incorporated into a master's degree educational-leadership program to create a clear connection between theory and practice.

Examining the impact of an intervention program and how it enhances the link between theory and practice stimulates critical reflection on how the program develops students' preparedness. Du Plessis and Sunde (2017) emphasize the need for a significant link between theory and practice in tertiary classrooms. The investigation, in addition, allows for documented and shared experiences that can benefit a targeted development of an educational-leadership master's program.

The study unveils how the intervention contact sessions were perceived by students as an effective design to connect theory and practice. The paper also reveals the challenges related to diverse tertiary student cohorts in a master's degree program for educational leadership. Student-teachers' preparedness for the teaching profession is examined (TEMAG, 2014). Kaiser et al. (2016) suggest that cognitive and situated experiences influence the capacity to perceive and interpret situations. Diverse higher-education classrooms pose specific challenges for educational-leadership programs to include effective internationalization and workplace relevance, and to improve the generalizability and content validity of the educational-leadership course.

The study investigates an intervention offered as part of an existing course over a period of one semester. The 
original course included a module titled "Meeting the challenges of educational change," one of five in the course, and included three topics. Topic one reviewed the concept of educational change with an emphasis on the contextual factors that influence the change process. Topic two investigated educational change through the prism of educational leadership with a focus on school management's effects on change. Topic three argued that teachers' learning is integral to the change process. The intervention contact sessions included an additional topic, Topic four, which sought to "Bridge the gap between theory and practice: Real-life experiences in the workforce."

Most of those who attended the course were international students from Borneo, Vietnam, China, Canada, Papua New Guinea, Tanzania and the United Kingdom. These students presented an abundance of knowledge and experiences in the classroom. Laschke and Blömeke (2016) emphasize that the image of teaching differs in different countries, as do specific expectations of educational and school leaders. These expectations have implications for the design of higher-education programs, such as the way an educational-leadership course prepares teacher-educators for specific environments. This phenomenon underscores the importance of relevance and the focus on current global educational issues that have significant implications for student-teachers' preparation for the profession. The investigation reflected on global perceptions about educational change and specific challenges in bridging the gap between theories for managing current and future changes in education and the reality inside schools. Ladson-Billings (1999) notes that teacher-educators should be purposefully prepared for diversity in their classrooms.

I argue that classroom participation in higher-education learning and teaching spaces, attention to diversity, student voice, internationalization and the richness of real-world experiences are restricted when teacher-educators do not design courses that accommodate multicultural and international students.

In previous decades, several studies have highlighted the value of attention to diversity in teacher education (Bondy, Schmitz, \& Johnson, 1993; Cannella \& Reiff, 1994; Cochran-Smith, 1991; Hood \& Parker, 1994; Sleeter, 2001). For example, Gay and Kirkland (2003) underline the role of critical consciousness in teacher education in relation to "the context of guided practice, authentic examples, and realistic situations" (p. 181). Sleeter (2001) notes that higher-education programs often provide "disjointed multicultural content" and that students view "programs as irrelevant to their preparation for teaching" (p. 212).

This paper has three goals:

1. to offer a description of an intervention in an educational-leadership course in a master's program that has a diverse international student cohort

2. to develop an investigation that offers a platform for student voice and agency in specific student groups that are often silent and not engaged (Chávez \& O’Donnell, 1998)

3. to offer a reflection on the critical consciousness of teacher-educators in designing programs and managing higher-education classrooms.

Continuous change and transformation in education pose significant challenges for school leaders, and shifts the focus toward ensuring that students receive quality preparation in educational-leadership programs to lead and support the teaching workforce. The internationalization and globalization of education requires a critical consciousness of the specific need for strong leadership in diverse school environments. However, Gay and Kirkland (2003) note that teacher education provides students with restricted opportunities for guided practice in self-reflection. In-depth self-reflection allows for an awareness of skills and leadership styles that require attention.

\section{Material Studied and Area Description}

Harman (2005) states that "the bulk of the Australian research effort on higher-education internationalization has been directed to specialized aspects related to the dramatic and important expansion in the export of higher-education services" (p. 122). The significance of this paper, although a small-scale study, lies in the in-depth investigation of lived experiences inside a higher-education classroom while it confronts the absence of in-depth critical analysis about the needs of an exceptionally diverse student cohort in an educational-leadership program. This concern involves reflecting on the current dilemmas, the realities of school environments and student voices in designing higher-education programs, specifically in an educational-leadership program.

Overlooking the value of student voices in diverse higher-education classrooms neglects the value and potential of real-life experiences and the richness that diverse experiences bring to the higher-education classroom and curriculum. Rizvi and Lingard (2010) claim that there was a global trend in relation to learning, and commonalities in perceptions about educational values. Comprehensive internationalization is the commitment and action to 
integrate international, global and comparative content and perspectives through teaching, research and service in higher education.

This paper highlights students' needs and expectations for internationalization in a course that acts as a foundation for constructing new knowledge, democracy, equality, educational policy, and value orientations in education systems. The investigation reveals students' lived experiences while focusing on students' expectations and perceptions of internationalization.

In addition, this study focuses on diverse learning communities and specific challenges within diverse higher-education classrooms and internationalization efforts. It also explores the specific challenges that the teaching method of collaboration poses in diverse student cohorts, and how this method could improve and enrich students' engagement.

A social constructivist learning perspective views the classroom space as a complex social entity. Sociocultural learning theories engage a diverse student cohort in complex learning spaces to provide new information and data about students' "real-world" experiences in higher-education learning spaces (Chambliss \& Schutt, 2003) and the way the learning space provides opportunities for learning from each other and stimulating students' professional and leadership development and preparation.

I argue that the internationalization of courses provides opportunities for the extended development of collaboration as a teaching and learning method, and that its efficiency is enhanced through an awareness of students' learning experiences (Kezar, 2005). However, internationalization becomes a challenge when there is no recognition of it as a descriptive and normative discourse that describes the relation between distant communities and the "value orientation" toward these communities (Rizvi \& Lingard, 2010, p. 24).

The intervention curriculum presents students with international case studies, reports and peer-reviewed scholarship for in-depth reflective discussions that focus on current global challenges in education. Current reports and research projects provide opportunities for contextualizing educational change through official surveys (Australian Education Union, 2009, 2010) and connecting theories to teachers' dissatisfaction with educational change, including the out-of-field phenomenon (Ingersoll, 2001a; Du Plessis, 2005), teacher turnover (Ingersoll, 2001b), teacher retention problems (Ingersoll, 2002), teacher attrition (Zepeda, 2006), and challenges in teacher placement, demand, and supply (McConney \& Price, 2009; Du Plessis, 2014). These case studies stimulate students' insight into the global educational concerns they will face as professionals and future leaders in education, while allowing them to contextualize the gap between theory and practice.

The project sought to stimulate and encourage student-teachers to actively engage in social interactions, collaborative group discussions and cooperative learning activities to investigate and discuss leadership styles, strategies, and skills (Peräkylä, 2004). Collaborative and cooperative learning activities stimulate in-depth discussion and capitalize on intellectual capacities (Kezar, 2005). The learning activities were based on social constructivism learning theories as students were challenged to share, discuss, and present personal viewpoints.

This study's goal was to connect theory with practice, to effectively prepare future educational leaders for the challenges that they will face (Du Plessis, Carroll \& Gillies, 2014). As such, this investigation was guided by a primary question: "How can a master's course prepare future educational leaders for specific challenges in the teaching workforce and workplace in a continuously changing environment?"

Sub-questions asked, "What are the needs of students in relation to an effective educational-leadership program?"; "How can a higher-education course bridge the gap between theory and practice?" and "What happens to student voice and agency in a diverse higher-education classroom?"

The search for answers and information on how to improve quality in an educational-leadership program informs the development of research questions against the background of a situated learning theory (Lave \& Wenger, 1991). The situated learning theory underlines the social process in which new knowledge is constructed through an awareness of the others' experiences and knowledge situated in a specific context and entrenched in a specific environment.

An epistemological diversity perspective was revealed through interview questions that engaged students with the following themes: "how to effectively manage diverse workplaces"; "how to lead teachers' learning while staying connected to the realities of the current school environment" and "the role of educational-leadership preparation in effective internationalization for education, educational policies and workplace complexities, such as teacher placement and management."

Gordon (1985) critically reflects on the concept of knowledge in teacher education and its importance to the field. 
The intervention course challenged students to actively engage in finding and discussing possible solutions. The solutions tapped into students' diverse backgrounds, knowledge, cultures and traditions through group discussions, individual writing, and presentations of leadership models. Incorporating shorter learning activities prompted broader engagement when sharing personal experiences. The investigation of the specific leadership course is vested in a critical reflection on the question, "Who produces knowledge and for what purpose?". Real-life experiences support socio-constructivist learning when students move toward an in-depth knowledge of the implications of issues on educational systems, leadership decisions, policies, and quality education and vice versa, with an opportunity to create deep learning (Fry, Ketteridge, \& Marshall, 2009).

Observing student engagement in the contact sessions provided an in-depth ontological foundation for the one-on-one interviews. Ontological awareness led to a clearer understanding of the current challenges in higher education in engaging diverse student cohorts. For example, these challenges include an awareness of the language of instruction when it is not the students' first language, as well as major cultural differences and traditions that are present in the learning space. An awareness of the underlying tension in multicultural and multi-linguistic higher-education classrooms (Cochran-Smith, 2000) can stimulate deeper reflection on course design, classroom management and the most suitable pedagogies for a specific situation. The observation protocol allowed the researcher to witness the engagement of students from diverse backgrounds to construct new knowledge. The discussion material included case studies in a global context, transnational peer-reviewed publications and international newspapers' representations of educational systems, teacher quality and practices as well as policy reports. Loughran (2013) suggests that teaching should be conceptualized as problematic, while accentuating the relationship between teaching and learning.

The investigation brought the reality of globalization to higher-education classrooms. Rizvi and Lingard (2010) note that the globalized world is inherently unequal and conflictual because different communities have divergent perceptions of globalization. Transnational research stimulates collaboration and discussion while providing an opportunity to construct new knowledge. Collaboration highlights the future leaders' common purpose, and scaffolding and deep learning were stimulated with the support of optional reading (Fry et al., 2009; Kezar, 2005). The voluntary investigation relied on experiential learning theory while encouraging collaboration and cooperative learning methods in which students discussed and investigated the challenges of educational change. This statement highlights the need to reflect and re-evaluate higher-education courses to move toward internationalization. The global realities that research can bring to the classroom can elucidate the impact of higher education on effective school leadership and teachers' learning (Du Plessis, 2005; Ingersoll, 2001b; Ingersoll, 2002). The paper contributes to the existing knowledge as it explores the quality of teacher education, prospective teachers' and leaders' school preparedness, and how effective higher education connects with the needs in the teaching workforce.

\section{Method}

The method employed for this small-scale exploratory study allowed an in-depth investigation of a master's student cohort in an educational-leadership program - a small and very diverse cohort that included graduate teachers and mature students from diverse backgrounds, nationally and internationally. It was not meant to be a statistical study, but an investigation into the effectiveness of a higher-education program to meet the needs of diverse students in diverse settings.

This study employed a qualitative approach that included semi-structured interviews, observations, two surveys, document analysis and a diary of reflective notes in the field (Seidman, 1998; Wengraf, 2001). The situated learning theory (Lave \& Wenger, 1991) informs the intense focus of the study on how students and their course coordinator perceive the effectiveness of the program and the higher-education classroom environment to support new knowledge construction that will prepare them for the challenges of leadership in the teaching workplace.

Participants included students and teacher-educators who volunteered to participate in the course intervention research project. The students were enrolled in an educational-leadership course in a master's degree program in one of the 2016 global top-60-ranked higher-education institutions. The student cohort included 20 internal, on-campus students and 5 external/distance students who were not involved in the intervention. One of the internal students terminated the course after four weeks, due to personal reasons.

The course coordinator was invited to participate in a semi-structured interview toward the end of the intervention that focused on his perceptions of students' preparation about working with diverse, multicultural and multi-linguistic populations, managing current dilemmas in education and developing into well-prepared future educational leaders (Freebody, 2003; Speziale \& Carpenter, 2007; Reisetter et al., 2004). 
In addition, the coordinator was asked how these implications posed challenges for higher-education courses to remain current in preparing future leaders (Freebody, 2003).

The focused observations provided information about students' engagement during the lessons, their learning activities (Ramsden, 2003) and their engagement in discussions and collaborative opportunities, especially for students who were non-native English speakers. The researcher recorded the diversity in students' engagement and how they collaborated and shared their personal experiences about leadership and management strategies, skills, pedagogies and behavioral attitudes.

The diverse student cohort was divided into four groups for the observation protocol. The first group included experienced teachers/mature students who have English as a native language. The second group included experienced teachers/mature students who have a primary language other than English (LOTE). The third group included English-speaking students who had no teaching experience. The fourth group included non-native English-speaking students who had no teaching experience. In addition, the researcher used a field diary to account for the time spent planning informal discussions with students, additional observations of interactions, and the details of the specific contact sessions, which were used as a data source (Mertens \& McLaughlin, 2003; Polkinghorne, 2005).

The first and second surveys provided information about students' expectations and lived experiences, their reflections on the intervention and its implications for their development as global citizens and future leaders in education. The participants were assured that any expression, idea or feeling was acceptable as long as it was real, and represented their personal perspectives on the course (Cohen, Manion \& Morrison, 2007; Polkinghorne, 2005).

The first, formative survey focused on expectations related to the primary question, which examined students' views of the effectiveness of a leadership course in preparing them for the teaching profession, and their understanding of global challenges in education. A second survey contained short, open-ended questions about their expectations at the end of the year, and provided a summative evaluation of how they perceived the knowledge they had gained on specific educational issues (Denzin \& Lincoln, 2005; Freebody, 2003). The appropriateness and strengths of the data collection included the breadth of the data resources (Hammersley, Denzin \& Lincoln, 2006) for understanding both expectations, and critical reflections at the end of the course. The open-ended questions also provided an opportunity for thematic analysis to organize the raw data into specific clusters of meaning.

Triangulation was achieved by using several data-collection methods (Cohen et al., 2007; Oliver-Hoyo \& Allen, 2006) that captured varied experiences and perceptions (Denzin \& Lincoln, 2005). Data triangulation allowed the researcher to move beyond a single perspective on the experience (Chambliss \& Schutt, 2003) and to compare data to obtain affirmation and consistency in the inquiry process. The triangulation included a careful review to achieve an accurate and valid description of participants' data (Hammersley et al., 2006; Oliver-Hoyo \& Allen, 2006). Participants' different views and perceptions were compared to increase the credibility and trustworthiness of the analyses and results.

The validity, consistency, and reliability of the data were demonstrated in the observations, two surveys that included additional open-ended questions, a semi-structured interview, and document analysis. These methods ensured data stability (Seidman, 1998; Wengraf, 2001) because information was provided from different perspectives (Gall, Gall, \& Borg, 1999; O'Cathain \& Thomas, 2006).

The validity of the data was tested according to Fokkema and Ibsch's (2000) definition for the reliability of design, which asks, "Will the same methods, used by different researchers and/or at different times, produce the same results?" Including multiple participants, students (from different backgrounds, genders and ages), lecturers and the course coordinator provided an in-depth understanding of the role of the course in preparing future teachers for challenges in educational change (Polkinghorne, 2005).

Efforts were made to cater for ethical concerns, including maintaining students' anonymity throughout the data-collection process. This concern was difficult due to the small size of the group in this phenomenological research design. The second ethical concern was related to protecting students' privacy and confidentiality (Hammersley et al., 2006) and was dealt with by de-identifying data and using pseudonyms. The third ethical issue was to ensure that the additional information, provided during the extra voluntary contact sessions, equally benefited the students. This was tackled by clearly stating that all students could attend the additional contact sessions, including those who did not participate in the data collection. The final ethical concern was that the course coordinator and students could have viewed the study as an intrusion into the existing course based on assessments, reading, and teaching, particularly in the way that the study affected the two planned assignments. The researcher 
responded to these ethical issues by ensuring that students understood that their participation was voluntary, and that the study was issue-related and not person-oriented, while further ensuring that all information would be handled responsibly and governed by the principle of confidentiality (Jones, Torres, \& Arminio, 2006). Results of the investigation were available to students on request (McMillan \& Schumacher, 2001), as stated in the letter of consent, and students were allowed to change the information they provided during the interviews (Jones et al., 2006; Wengraf, 2001).

The study included two surveys — one pre-course formative and one post-course summative—which included written responses to open-ended questions, an hour-long interview with the course coordinator and observations from 14 contact sessions. The document analysis included a final assignment of approximately 3000 words. Students' outcomes and achievements were analyzed as quantitative performance data. Informal discussions allowed students and the two teacher-educators to share perceptions of how the design of a master's educational-leadership program could effectively accommodate diverse student cohorts and successfully tap into the experiences, knowledge and engagement of diverse student cohorts.

\section{Techniques}

The small-scale exploratory qualitative study offered unique opportunities for the researcher to build trust relationships with the students and course coordinator, and move close to the real-life experiences within a diverse higher-education classroom. The global call for quality teacher education motivated the researcher to develop a technique that would unveil the truths from the field: in this case, diverse students who required preparation for diverse leadership settings.

The search for an in-depth understanding of the impact of a diverse student cohort and their course coordinator on new knowledge construction made it necessary to employ a combination of philosophies and specific theories in order to develop a reliable technique. The social constructivist interplay between teaching and learning provided a framework for exploring the lived experiences of the diverse and international student cohort in this study.

Additionally, the research question, "How can a master's course prepare future educational leaders for specific challenges in the teaching workforce and workplace in a continuously changing environment?" situated the students and an understanding of their learning needs at the center, and is embedded in the situated learning theory that pays attention to social and environmental influences. A deeper understanding of the needs of participants in this study can only develop through a close focus on what is said and how it is said.

Gadamer (1975) claims that being-in-the-world involves the situatedness of Dasein, which is how human beings who are immersed in this world share it with others through caring, thinking, doing, and using language to understand. This argument relies on Gadamer's view of "being-in-the-world" with others to understand specific needs for professional development. The question also accounts for Van Manen's (1990) notion that lived experiences reflect "the life-world" of an individual and develops a "deeper understanding" (p. 9) of needs, expectations and perspectives. The lived experiences of student-teachers in higher-education classrooms while they engage in discussion around concerns in education influences their professional preparation and development for the workforce. Gadamer attends to the nature of hermeneutic experiences (Gadamer, 1976; Vessey, 2007) to form an interpretive understanding of what is shared and who is sharing. First-hand experiences convey real-life stories that can inform the development of the most appropriate and informative student-teacher programs.

This paper underlines the influence of higher-education courses on student-teachers' "own Being" (Van Manen, 1990, p. 176). Our argument confronts and investigates higher education's learning space and habitus, its effectiveness for accommodating student-teachers as global citizens, the course's success in recognizing student-teachers' lived experiences and feelings of "belongingness" (Gadamer, 1975, p. 416), and the implications for preparation in the education profession.

The discourse analysis informed the development of specific themes and sub-themes. Using social integration and triangulation in the data analysis from several data sources helped us to avoid errors when drawing conclusions (Hardcastle, Usher, \& Holmes, 2006; Oliver-Hoyo \& Allen, 2006).

Vygotsky's (1978) social constructivist theory focuses on effective learning through careful guidance from a more knowledgeable other, and views the lived experiences of diverse students as the more knowledgeable others of their specific cultural backgrounds, which can guide the construction of new knowledge. Grondin (2002) explains that the Gadamerian notion of practical wisdom includes self-understanding within a practice situation, whereas distance from practice "can induce a distortion" (p. 5). He further notes that Gadamer upholds attentiveness as a mode of knowledge that has potential as an application of understanding and reflective knowledge of the human experience. 
Hermeneutics is a practical philosophy that views participants' truths as independent of scientific methods. It views knowledge as situated in history, traditions and culture, whereas understanding depends on verbal and nonverbal linguistics. The discourse analysis unveils the truths from the field to support a holistic understanding. Gadamer's (1975) hermeneutic philosophy of "understanding the whole in terms of the detail" (p. 291) supports the critical need to comprehend specific details of the lived experience to create an in-depth understanding of its meaning for professional development. The aim is to interpret specific linguistics that reveal the participants' personal needs in relation to the course, internationalization of the course and students' learning needs, as well as their implications for course development, globalizing students' learning experiences, and the current educational issues and lived experiences that encompass these challenges.

Moran and Mooney (2002) claim that a person's body is the vehicle for perceptions, experiences, internalized knowledge and action. This paper argues that student-teachers in an educational-leadership master's degree program have explicit needs for in-depth, integrated discussions about school leaders' real-life experiences on a global stage. Diverse student cohorts bring an abundance of diverse experiences and knowledge to higher-education classrooms.

\section{Results}

The results include discourse and content analysis of raw data from interviews, informal discussions, observations, the student assignments, two surveys and notes from the field diary to provide a holistic picture (Cohen et al., 2007) of the investigation. The various sources were used to offer truths from the field through different angles. The argument in this paper focuses on the effectiveness of higher-education programs, how successfully they link with diverse workplaces and the diversity of students' needs.

Students' responses to the surveys were analyzed in two ways. First, short answers were analyzed by counting the frequency of responses in each category, and the responses were presented in graphical form. Second, the responses to open-ended questions were thematically analyzed, and these responses, along with the data from the interview with the course coordinator, were grouped to portray the entire picture (Patton, 2002). The thematic analysis (Patton, 2002) from the data collected through the open-ended questions, course coordinator interview and classroom observations is provided in a graph that highlights the variation in students' expectations of sharing real-life experiences and observations of collaborative discussions in the classroom. These results were supported with field notes (Swidler, 2000) about the dispositions of and informal interactions with peers, the course coordinator and the researcher.

The results highlight three influential points of impact in initial teacher training. The first point was effective and targeted internationalization of the curricula. The second point was recognizing there should be an awareness of the available multi-faceted information and the abundance of new knowledge that diverse student cohorts bring to higher-education classrooms, such as language issues. The third point was that the manner in which teacher-educators and the course coordinator managed diverse higher-education classroom complexities has the potential to enhance or limit the construction of new knowledge.

Students shared that the most persuasive learning experiences were their exposure to reports of real-life experiences in which educational-leadership decisions had an influential impact on the teaching and learning environment, which was explained by their peers from culturally diverse environments and international backgrounds. Pseudonyms were used when presenting the results to protect the participants' privacy. Nick, a student in his final year, shared his expectations for an education leadership course: "Good discourse with other students from varying national and cultural backgrounds..."

Student demographics and cultural backgrounds had a significant impact on the planning of teaching and learning activities in the sessions organized as course-design interventions. The researcher adjusted the teaching methods and incorporated teaching approaches to ensure that all students had a voice, with a specific focus on multicultural agency. Understanding how this specific educational-leadership course effectively prepares student-teachers as leaders and global citizens stimulates a critical reflection on the gap between theory and practice in the course. The internationalization of an educational-leadership course prepares prospective leaders for success, because knowledge construction occurs against a background of different perceptions, expectations, and needs from a diverse student cohort and demonstrates how the course and program-design meet expectations.

Lia (a participant) shared this: "I would be able to function effectively as an educational leader in my environment if the course focuses more on practical work... what to do in several study cases or experiences...life experiences from the educators..."

Engaging students and demonstrating the significance of their voices in the building and extension of the course 
curriculum beyond the classroom influences students' perceptions of their preparation for possible leadership roles. The active engagement opportunities created for students through case study discussions influence their perceptions of the course's effectiveness and student performance, despite accounting for several additional variables.

\subsection{The First Survey: Student Expectations}

The purpose of the first survey was to develop an understanding of students' expectations in a master's degree educational-leadership course. This survey focused on the perception data to obtain an in-depth understanding of the question, "How does an educational-leadership program and its implementation prepare student-teachers for challenges in continuously changing school environments?" The first survey enquired about master's degree students' expectations for the skills they would acquire through the educational-leadership program. Since the number of eight primary themes emerged from this survey:

1. developing general leadership skills

2. knowledge about organizational leadership

3. skills for effective teaching-workforce management

4. sharing and in-depth discussions of real-life experiences

5. exposure to leaders with expertise in the field

6. opportunities to critically reflect on different leadership models

7. expectations for continuous adjustment and assessment of the course material

8. targeted program design and suitable methods for delivering course material.

Lia shared her perspective about adjustments needed to make the course design more relevant for the diversity of this specific student cohort: "I would like the course to improve in delivering the course material." She further noted that the absence of collaboration and in-depth discussions between fellow students from different cultural backgrounds and educational systems hindered learning opportunities, and limited valuable exposure to diverse and real-life school situations.

Another student, $\mathrm{Li}$ viewed her development as a prospective leader as follows: "I would be able to function effectively as an educational leader in my environment if the course focused more on presenting and analyzing current leadership models or PLC (Professional Learning Community) models from some outstanding educational systems..."

The responses to the survey's open-ended questions also highlighted students' perceptions of how an educational-leadership program could improve their leadership competencies through the course. Nic, an older student, suggested that the course design should “...introduce some case studies or real life examples to discuss..." In addition, the open-ended questions revealed how educational-leadership students perceived their attentiveness to current issues and concerns in education.

The intervention in the educational-leadership program focused on current issues that present major challenges to school and educational leaders. During one of the intervention contact sessions, the students were asked to examine, reflect upon and discuss relevant, current case studies and recent reports on workforce and workplace issues in the international arena. Scholarly readings with a specific focus on the teaching workforce and workplace issues from Norway, Germany, the United States, the United Kingdom, Australia and South Africa were provided to supplement current reports and newspaper articles on the challenges of teachers' employment conditions and placements, such as teaching in subjects or at grade levels without the appropriate qualifications or expertise (the out-of-field phenomenon). Students were expected to engage in in-depth reflective discussions about the implications of these situations on leadership. Bob, an international student with an indigenous background who was preparing for a school leadership role, exclaimed, "...I am interested in...and honestly, quite shocked knowing that the out-of-field phenomenon happens in the Australian educational system..."

There was concern about the disconnection between higher-education programs and the reality in the workplace, as well as the capacity of these programs for preparing school-ready leaders. The students' responses clearly indicated that the shared experiences were of great value to them. They were eager to collaboratively discuss with trusted peers real-life issues that existed within schools and classrooms. They expressed a desire to know more about different educational systems and specific issues, dilemmas and concerns within these systems. 


\subsection{The Second Survey: Student Considerations and Insights}

The purpose of the second survey was to reveal students' summative perceptions, as prospective educational leaders, about their preparation for leadership roles and challenges. In addition, the survey focused on the lived experiences and insights from the students who attended the intervention contact sessions. The first section of the summative survey reviewed specific concepts that were examined during the intervention with Likert-style statements to explore students' considerations, experiences and insights in relation to the content introduced during the intervention contact sessions. The themes examined in the statements in the first section of the survey included current teaching workforce and workplace issues, such as teacher turnover, retention, attrition, and teacher placements (especially in the out-of-field phenomenon). In addition, the survey posed open-ended questions about management skills for tackling the current issues in education, and about how real-life experiences influence this skill development. The survey data showed that the students involved in this program intervention either agreed, or strongly agreed, that the intervention contact sessions supported the following:

- deeper reflective insights into specific leadership skills and an increased awareness of the current challenges that educational leaders and, specifically, school leaders face

- effective preparation for educational transformation and change while providing an international scholarly focus on specific issues and concerns in educational change through the provision of readings and resources

- in-depth discussions to share realities from different educational systems

- developing a comprehensive awareness of teaching workforce and workplace issues, and their impact on school leadership models, styles and quality education

- awareness of the implications of teacher turnover, teacher retention and teacher attrition on school improvement plans.

The results of the open-ended responses indicated that the intervention stimulated the construction of new knowledge and had positive implications for students' preparation for challenges in the workforce and workplace. Lia highlighted a component that she would benefit from, once she was back in the school environment in a leadership role: "The most important concept I have learned through the course was the effect of teacher positions and the out-of-field phenomenon." Lana underscored the value of internationalization in the intervention session curriculum: "...lectures were providing a wide range of materials to learn about several concepts in this course." Nick explained that the design of the intervention course reminded him of his passion to help and support colleagues and made the leadership experience real. He reflected on the intervention program: "...the course was very useful, with good content. I enjoyed it and learned a lot." Kay shared how the intervention contact sessions encouraged her to read more about specific issues, and improved her capacity to have a deeper understanding of the specific issues that impact the teaching and learning space: "I applied the information on instructional and transformational principles and how the focus on learning may impact teachers and students."

Li mentioned, "...the extra contact sessions helped me broaden my knowledge about leadership practices in Australia." $\mathrm{Li}$ further added, "I am interested in, and honestly, quite shocked when knowing that the out-of-field phenomenon happens/occurs in the Australian educational system. I hope to learn more on how the Australian government copes with this issue effectively, and maybe I will apply what I've learned into my leadership practices if this phenomenon happens at my school. I am also keen on the issue of how developed countries enact policies to increase teacher retention..."

The participating students' responses to the content and methods used during the intervention sessions showed that there was a positive learning experience that effectively bridged the gap between theory and practice. The results provided information that answered the research question, "How can a master's course prepare future educational leaders for specific challenges in the teaching workforce and workplace in a continuously changing environment?" Open-ended questions about the implications of the intervention for the existing course examined the following areas:

- students' experiences about the influence of the intervention sessions on meeting the requirements of the course assignments

- the impact of the new and workplace-related information in the intervention sessions on course assignments

- the value of the scholarly work provided as part of the intervention sessions to capture the current international workplace issues, and their impact on the quality of education.

The students participating in the intervention contact sessions further indicated that they found the additional 
discussions about practical issues that leaders face in the teaching workforce and workplace stimulating, enjoyable and a valuable opportunity for constructing new knowledge. The international students' agency inspired thought-provoking discussions of dilemmas in effective school improvement strategies.

\subsection{Higher-Education Classroom Pedagogies: Observing and Comparing the Impact on Student Voices and Verbal Engagement}

The observations supported the reflections on student voice and agency in the different contact sessions. The observation protocol explored the prevalence of students' voices in the original course contact sessions, and compared the presence of students' voices in the intervention contact sessions. This protocol also analyzed how the teacher-educator managed and encouraged students' voices during the original contact sessions, and acknowledged diversity and multicultural backgrounds in the higher-education classroom.

The investigation focused on equality in students' participation in collaborative and spontaneous discussions. Critical reflections on students' voice and agency as an enacted curriculum in this educational-leadership program revealed noticeable changes in students' verbal participation after changing the program's design. During the additional intervention contact sessions, the researcher, who had the role of a teacher-educator, focused on the diversity of the student cohort in relation to multiculturalism, language ability and confidence in sharing experiences. The goal was to highlight the value of student voice to obtain information about international educational systems and internationalization in the course programs. In-depth discussions on real-life case studies, prompted by specific questions about leadership decisions, improvement policies and issues in the workplace, provided new information and knowledge.

Although the course coordinator and the responsible teacher-educator focused on class discussions as a whole, unawareness of the disappearance of the multicultural student voice created a classroom situation that hampered the construction of new knowledge.

Students' attendance was recorded to inform the results and perceptions of students' voices and agency in this diverse classroom. Figure 1 demonstrates the results for the engagement of different groups of students. Table 1 and Figure 1 provide a holistic view of the student group participation rate in this educational-leadership classroom during the original and intervention contact sessions. The intervention contact sessions included several teaching pedagogies, resources, and content, such as issues across different educational systems with a focus on current international educational challenges.

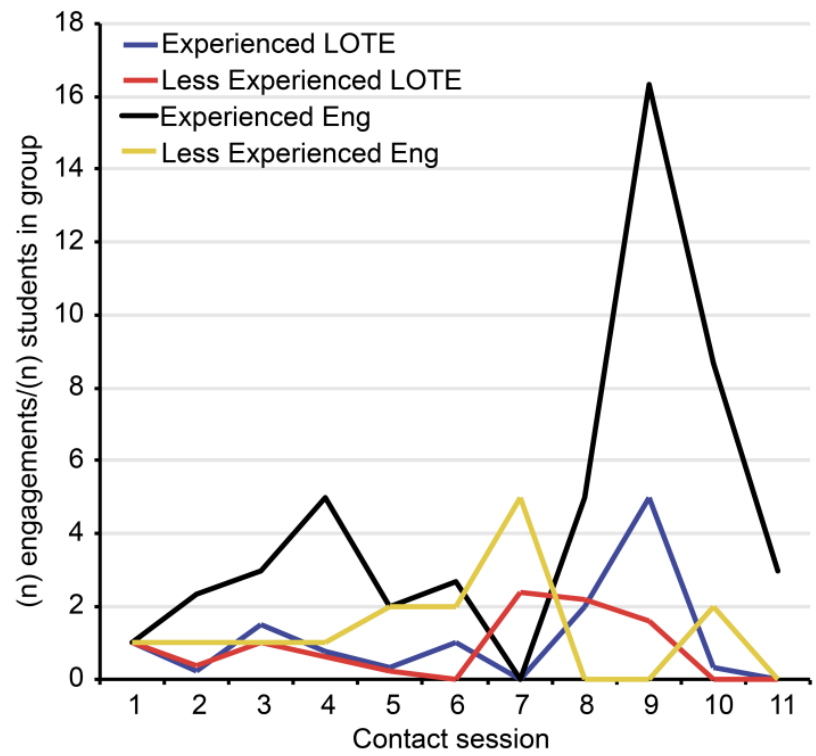

Figure 1. Comparing students' voices from different sessions during the research intervention in an educational-leadership program

The results showed that multicultural students who spoke a language other than English (LOTE) tended to be more engaged when there was a stronger focus on internationalization in the curriculum. The focus of the intervention lessons on globalized education appeared to encourage students from diverse backgrounds to share their experiences as well as their education and knowledge backgrounds. The students who had multicultural backgrounds became 
more engaged in contact sessions 3, 6, 7, 8 and 12, which were the intervention curriculum sessions.

The data in Figure 1 can be interpreted as follows. In contact session 1, the introduction session to the course, all students participated at least once in the session (a rate of 1) because the course coordinator requested that students share something about themselves. However, this valuable opportunity to collect background knowledge about students was not fully explored.

During contact session 2, the experienced/mature native English-speaking students began to dominate the class discussions. Verbal engagement in the two student groups that spoke a language other than English (LOTE) decreased, whereas verbal engagement by less-experienced native English speaking students remained constant.

In session 3, the first session that enacted the intervention curriculum, there was an improvement in LOTE students' verbal engagement, whereas there was a continued increase in experienced/mature English students' engagement.

Sessions 4 and 5 demonstrated a reduction in LOTE students' engagement as the two English-speaking groups dominated the classroom discussion.

Notably, intervention sessions 6 and 7 demonstrated a dramatic increase in engagement from the less-experienced LOTE students, whereas the experienced/mature student groups were absent from these sessions. These results demonstrated the underlying classroom cultures, traditions and pedagogies and their influence on effective engagement and collaboration in diverse classrooms.

Sessions 7 through 9 demonstrated a possible increase in confidence in the LOTE groups as their verbal engagement remained positive, with the English-speaking groups present and active. The overall summary demonstrated that experienced English-speaking students were very verbally engaged, confident and almost dominating. Less-experienced English-speaking students demonstrated consistent growth in verbal engagement during all the attended sessions. They demonstrated overall positive verbal participation with an increased rate over time.

Both LOTE groups appeared very reserved and cautious, and participated in almost opposite ways compared to the English-speaking students, except in the intervention sessions. The intervention was conducted over three consecutive weeks (sessions 6,7, and 8). During these sessions, there was a focus on student voice, accommodating diversity, and collaboration among international students from multicultural backgrounds.

The results showed improvement in student voice and confidence in sharing information from international education systems after session 6. Real-life case studies and literature closely related to the specific issues under discussion were presented, and critical inquiries were stimulated during the intervention contact sessions.

Figure 1 displays how the presence of student voice changed during the different contact sessions; how students' confidence and courage influenced the level of student voice; as well as how one group could dominate other groups. This finding suggests that it may be important to develop specific strategies for managing collaboration as a teaching method, adjusting teaching methods in accordance with group dynamics and changing approaches and presentations.

This data set does not demonstrate the contents/topics discussed that may have influenced the relative levels of engagement. It is assumed that the topics were similarly relevant to all four groups, and that the groups would participate in discussions on an equal basis. Learning in a diverse higher-education classroom offers the potential to explore new information from diverse international educational systems. However, observations of the students, contact sessions, and the teacher-educator showed that the classroom management and course design reflected awareness or unawareness of the differences in the class composition, and solved this by encouraging involvement in the more complex individual or group situations in the class.

Language is a barrier that should be recognized because it limits individuals' ability to confidently express themselves in an open forum. (This is a major assumption that is based on observations during the class sessions.)

The observation data provided in the diagram shows that the teaching method of collaboration may encourage lessconfident students to share their experiences and viewpoints. This is related to the question, "How can a master's course prepare future educational leaders for specific challenges in the teaching workforce and workplace in a continuously changing environment?" while highlighting the change that occurs in the lived experiences of students when there is effective internationalization of programs. The observation method revealed significant information about what occurred during collaboration and group discussion. The uneven engagements of students in collaborative learning activities led to the development of unequal learning opportunities.

\subsection{Teacher-Educator Agency and Perceptions}

The interview with the course coordinator provided answers to the research question in the form of data that 
explained his perception of students' specific needs. His perceptions of the complexity of the management of collaboration and group discussions in his classes were informed by the following response:

"I guess...obviously the internal cohort...not so much the external cohort...the internal cohort is more international students...the downside of this is that there are major cultural differences...but it is not so straightforward...[uncomfortable laugh and long silence]..."

Although the students indicated in the surveys that they often felt unprepared for the challenges of educational change in their work environments, and wanted to learn more from each other, the course coordinator said, "Hm...there is probably nothing that I would change to those key themes...I [would] probably maintain those, but I am always on the lookout for readings...I would replace some of the readings."

However, the students indicated that they found it difficult to understand readings when they were presented by fellow students. Lia said, "...they were barely understood by some of us..." The students need an opportunity to discuss specific educational changes and challenges to receive feedback on the views and practices described in the literature.

\subsection{Reflections from the Field Diary}

The field notes supported the search for truth by recording informal conversations and interactions, and by observing all the contact sessions with a specific focus on students' willingness to share their own experiences about educational leadership. Informal discussions with students revealed their extraordinary focus on the assessment assignments and not on the learning process. One student shared information about how she learned more from her voluntary practical work-experience hours at Indigo State High School ${ }^{1}$ than from her course work. Four international students with diverse backgrounds shared a strong need for literature from "other countries" and not predominantly from "Western countries" to be taken up in their prescribed reading list for the specific course. One student from Tanzania shared, "We have so much to learn from each other", but underlined that such opportunities need to be carefully designed. The researcher's field diary reported significant information from several students who did not participate in the class discussions but comfortably participated in the smaller and more infrequent group discussions.

\subsection{Document Analysis: Assignment and Performance Data}

The master's student cohort that participated in the intervention were asked to voluntarily provide their final assignment outcomes as part of the document analyses. These confirmed that opportunities to build the capacity for student voice, such as transforming pedagogies, collaboration, in-depth group discussions and sharing real-life experiences, for example an opportunity to have a panel discussion with current school principals, can provide students with substantial learning opportunities (Fry et al., 2009).

Table 1 shows the performance data from students who participated in the intervention contact sessions and provided permission to use information from their primary assignment.

Table 1. Student achievement for the final written (3000-word) assignment

\begin{tabular}{l|lll}
\hline $\begin{array}{l}\text { Students who } \\
\text { volunteered for } \\
\text { individual scores to be } \\
\text { published } \\
\text { (Pseudonyms) }\end{array}$ & Individual score & $\begin{array}{l}\text { Average score for } \\
\text { students who } \\
\text { participated in the } \\
\text { intervention contact } \\
\text { sessions }\end{array}$ & $\begin{array}{l}\text { Average score for } \\
\text { students who did not } \\
\text { participate in the } \\
\text { intervention contact } \\
\text { sessions }\end{array}$ \\
\hline Nick & $67 \%$ & & \\
Bob & $64 \%$ & & \\
Li & $72 \%$ & $70.5 \%$ & $64 \%$ \\
Lia & $75 \%$ & & \\
Sue & $71 \%$ & & \\
Zoe & $73 \%$ & & \\
Caz & $71 \%$ & & \\
Kay & $71 \%$ & & \\
\hline
\end{tabular}

The results showed that the students who participated in the intervention curriculum that focused on real-life 
experiences, internationalization and multicultural backgrounds and different educational systems were stimulated and intrigued by educational leadership, by the impact leaders have on the teaching workforce and workplace, and vice versa. These students demonstrated a clear alignment between theory and practice in their final assignment and obtained a higher average score on their assessment task.

The students who did not participate in the intervention due to the extra work, and to the additional intervention contact sessions, obtained a lower average score. Although several factors may have impacted the students' outcomes, the performance indicators for students who participated in the intervention showed that they obtained a level of deep learning by applying the new knowledge from the intervention to the assignment requirements.

However, it is important to note that several factors, such as student commitment, drive and responsibility, were not assessed in the performance data. Although the sample size might seem small, it should be kept in mind that the intervention study involved voluntary participants from a single postgraduate educational-leadership course.

\section{Discussion}

The discussion primarily highlights four points:

1. the teacher-educator's role in creating equal opportunities for students' voices and agency

2. connecting theory and practice in an educational-leadership course

3. course design and possibilities to acknowledge diversity

4. an awareness of the benefits of internationalization in a course.

Barry and Lechner (1995) note that although student-teachers are aware of diversity in schools and the resulting challenges, "most felt unprepared" (p. 211) for what awaited them in the school environment. The effectiveness of a higher-education, educational-leadership course is closely connected to how it relates to the students' realities, needs and their expectations to develop a preparedness for the workplace. Students are ready to face global challenges; however, this investigation showed that higher-education program designs need to stay connected to a global space when they deal with students' preparedness for professional challenges. The findings show that students bring a richness of knowledge to the classrooms for teacher-educators to explore.

\subsection{Student Voice and Agency: Creating Equal Opportunities to Have a Voice and Agency}

Hargreaves (1998) asserts that emotions, passion and dispositions form the heart of teaching, and that an individual's beliefs, cultural knowledge and environment impact his or her success. The data demonstrate that transforming higher-education courses and improving the quality of teacher-education programs can be supported by collaboration as well as by an awareness of the value of student voice and agency.

Smyth (2013) further accentuates the value of collaboration between teacher-education and the school to develop the "socially just school" (p. 114), in which "socially" implies equal attention to the multiplicity of voices. Giroux (1986) claims that voice refers to the various measures through which students and teachers actively participate in dialogue.

The primary points underlined in the results are the absence of student voice in the design of the specific educational-leadership program, managing the higher-education classroom environment to accommodate diversity, an awareness of the disappearance of student voice, especially for LOTE students, and how this disappearance influences diversity and sharing valuable information. Crose (2011) underlines that "language plays a crucial role" (p. 390) in higher-education classrooms because it affects confidence. Findings in this study showed that, if not effectively managed by teacher-educators, it has significant implications for new knowledge construction.

Cannella and Reiff (1994) note that highlighted educational programs are often not well thought through, and "depend mainly on the interests of individual professors" (p. 221). The interview and survey data accentuate the importance of diversity and a focus on local and global curricula for preparing teachers because local prosperity is related to global co-prosperity. The results suggest the need for a global, comparative and international context to inform existing courses, foster global relations and improve cross-cultural understanding.

\subsection{Connecting Theory and Practice in an Educational-Leadership Course}

The data in this investigation highlighted that internationalization in higher education should close the gap between theory and practice, and has clear implications for outcomes related to students' engagement and active participation in higher-education learning spaces. Sleeter (2001) notes that life experiences provide opportunities to draw from and construct appropriate pedagogy; however, higher-education "programs were not designed to extend what students already knew" (p. 212). The resources used in the intervention curriculum, such as literature, international education reports and newspaper claims, challenged students to engage in discussions and share their understanding of specific 
concepts, including results-driven school environments, school improvement policies, and teacher attrition, turnover rates and retention, while reflecting on the effect of student-teachers' learning and its impact on educational change.

\subsection{Course Design: Possibilities for Diversity}

Harman (2005) identifies failures of higher-education courses to utilize the possibilities that diverse student cohorts have to offer for quality higher education through collaboration: "What is not clear, however, is how seriously these failures in social interaction are viewed by international students themselves and to what extent this affects their course satisfaction" (p. 129). The strength of this study lies in the platform it provides for students to voice their experiences and perceptions. The findings in this study show that diverse student cohorts with different language and cultural needs become more confident in sharing their lived experiences and backgrounds by recognizing that all students need to become global citizens. Differing experiences, background knowledge, and students' situations suggest different learning needs that underscore the importance of bridging the gap between theory and practice.

Rizvi and Lingard (2010) note that globalization has major implications for social institutions, a sense of belongingness and identity. The higher-education learning space benefits from increased global mobility among students. However, this means that higher-education providers are responsible for providing internationalized curricula to prepare for global citizenship without national boundaries. The results demonstrate that the student-teachers involved in this educational-leadership course expected a curriculum that would prepare them for the diversity and challenges that they would face as leaders in their schools.

Crose (2011) notes that students' relationships with peers and faculty staff are vital to their success. The intervention contact sessions provided collaborative learning activities that stimulated discussions across cultures by incorporating small group discussions and cooperative learning as teaching methods to accommodate the diversity in the student cohort. Importantly, these sessions revealed the impact of teacher-educators on the way in which they manage diverse classrooms and apply pedagogies.

This study highlighted major challenges for course coordinators in internationalizing their courses and ensuring that they are aware of their students' needs, especially in diverse student communities that have specific language and cultural needs. Students should be encouraged to take risks in their learning and construct new knowledge that is embedded in group discussions (Crossley \& Watson, 2003). This research project revealed the importance of leadership preparation and teachers' learning on educational change and the value of comparisons across different societies.

\subsection{The Benefits of Internationalizing a Course}

Internationalization in the intervention contact sessions shifted the focus toward global educational issues and international concerns related to quality education, students' achievement in the classroom and leaders' impact on the teaching and learning environment. Bausmith and Barry (2011) prompt researchers to explore possibilities for enhancing teachers' pedagogical content knowledge. This study indicates that it is important to align pedagogical content knowledge with theory, practice and relevant workplace situations. Prospective leaders' learning experiences connected to real-life and current issues stimulate an in-depth understanding of leaders' impact on quality education.

The students expressed willingness to discuss social differences and their implications while demonstrating eagerness to share experiences and perspectives. Shared opinions about the structure of different educational systems and discussions of the benefits and limitations of leadership models and styles created a hands-on leadership course. The intervention contact sessions provided students with an opportunity to reflect on and evaluate their expectations for the current course as well as their level of development as future teachers and educational leaders. It provided an individual critical analysis of what they needed to improve and encourage active engagement in their development as future decision-makers in an international arena.

The observations from the 14 contact sessions led to an awareness of the dilemmas that teacher-educators face in diverse classrooms, and generated new information on teacher-educators' impact and opportunities to ensure that every student is heard. The interview and observation data showed that an approachable, empathetic, and engaged teacher has a large impact on the willingness of diverse students to participate in discussions and disclose personal experiences. Course coordinators directly influence the development and engagement of students at different levels.

Internationalization in courses is not a choice; it is essential for acknowledging the importance of becoming global citizens who are aware of students' background knowledge to encourage them to take risks in constructing new knowledge. 


\section{Conclusion}

De Vita and Case (2010) emphasize that the internationalization of higher education needs critical reflection on practices to inform the desired reform, based on results of dialogue and debate of those actively involved in higher-education classrooms.

This small-scale investigation focuses on these real-life experiences while it highlights three influential points of impact in initial teacher training:

1. effective and targeted internationalization of the curricula

2. an awareness of the available multi-faceted information and the abundance of new knowledge

3. a revelation of the potential to enhance or limit the construction of new knowledge.

McIntyre, Pedder and Rudduck (2005) highlight the lack of attention to student voice and the many "excuses" for not listening to or actively seeking out students' views in higher education. They further emphasize that being responsive to pre-service teachers' voice, change, and developing pedagogies for the future can lead to immediate and powerful outcomes. Student demographics have a substantial influence on the enacted curriculum, the effectiveness of collaborative teaching methods, learning activities, successful engagement in group discussions and assessment processes. The teacher should manage these with great care to avoid missing out on learning opportunities and to reverse the decreased engagement of less confident students.

This study plays an informative role in the preparation of future educational leaders, their skills, strategies and roles in developing successful and effective school environments. The intervention program demonstrated utility and transferability of the data through students' perceptions and descriptions of different viewpoints and teacher-educator perspectives. The findings are applicable to similar global higher-education situations. This study liberated and empowered students from diverse backgrounds to add to the construction of new knowledge.

Diverse groups of students bring richness and depth to the enacted curriculum. However, the teacher-educator must unlock this potential as well as the curriculum, course design, resources and pedagogies that are used in the higher-education learning space. Internationalizing courses relies heavily on teaching methods, managing learning environments, and designing assessment tasks to improve learning success. These opportunities are rarely optimized by teacher-educators. Master's degree students in an educational-leadership program expect to use current, international resources and scholarly work, relevant case studies, and small group discussions with continuous feedback to encourage active engagement and risk-taking in learning by sharing their diverse experiences.

\section{Acknowledgements}

The author wishes to acknowledge the student cohort and course coordinator involved in this master's degree educational-leadership program. They volunteered their time and perceptions to develop an awareness of the complexities within higher-education classrooms while enhancing the development of program design according to diversity and internationalization.

\section{References}

Australian Education Union. (2009). The state of our schools survey 2009. October 2009. Retrieved from http.//www.aeufederal.org.au/Publication/2009/SOSreport.pdf

Australian Education Union. (2010). The state of our schools survey 2010. October 2010. Retrieved from http.//www.aeufederal.org.au/Publication/2010/SOSreport.pdf

Barry, N. H., \& Lechner, J. V. (1995). Preservice teachers' attitudes about and awareness of multicultural teaching and learning. Teaching and Teacher Education, 11, 149-161. https://doi.org/10.1016/0742-051X(94)00018-2

Bausmith, J. M., \& Barry, C. (2011). Revisiting professional learning communities to increase college readiness: The importance of pedagogical content knowledge. Educational Researcher, 40, 175-178. https://doi.org/10.3102/0013189X11409927

Bondy, E., Schmitz, S., \& Johnson, M. (1993). The impact of coursework and fieldwork on student-teachers' reported beliefs about teaching poor and minority students. Action in Teacher Education, 15, 55-62. https://doi.org/10.1080/01626620.1993.10734410

Cannella, G. S., \& Reiff, J. C. (1994). Teacher preparation for diversity. Equity and Excellence in Education, 27, 28-33. https://doi.org/10.1080/1066568940270305

Chambliss, D. F., \& Schutt, R. K. (2003). Making sense of the social world: Methods of investigation. London: Pine 
Forge Press.

Chávez, R. C., \& O’Donnell, J. (1998). Speaking the unpleasant: The politics of (non)engagement in the multicultural education terrain. Albany: State University of New York Press.

Cochran-Smith, M. (1991). Learning to teach against the grain. Harvard Educational Review, 61, 279-310. https://doi.org/10.17763/haer.61.3.q671413614502746

Cochran-Smith, M. (2000). Blind vision: Unlearning racism in teacher education. Harvard Educational Review, 70 , 157-190. https://doi.org/10.17763/haer.70.2.e77x215054558564

Cohen, L., Manion, L., \& Morrison, K. (2007). Research methods in education. London: RoutledgeFalmer.

Crose, B. (2011). Internationalization of the Higher Education Classroom: Strategies to Facilitate Intercultural Learning and Academic Success. International Journal of Teaching and Learning in Higher Education, 23(30), 388-395. Retrieved from http://www.isetl.org/ijtlhe

Crossley, M., \& Watson, K. (2003). Comparative and international research in education: Globalisation, context and difference. London: RoutledgeFalmer. https://doi.org/10.4324/9780203452745

Denzin, N. K., \& Lincoln, Y. S. (2005). The SAGE handbook of qualitative research. Thousand Oaks: Sage Publications.

De Vita, G., \& Case, P. (2003). Rethinking the internationalisation agenda in UK higher education. Journal Of Further And Higher Education, 27(4), 383-398. https://doi.org/10.1080/0309877032000128082

Du Plessis, A. (2005). The implications of the out of field phenomenon for school management (M Ed dissertation). UNISA, Pretoria. http://uir.unisa.ac.za/handle/10500/2197

Du Plessis, A. (2014). Understanding the out-of-field teaching experience (Doctoral thesis). The University of Queensland, Brisbane, Australia. Retrieved from http://espace.library.uq.edu.au/view/UQ:330372

Du Plessis, A., Carroll, A., \& Gillies, R. M. (2014). Understanding the lived experiences of novice out-of-field teachers in relation to school leadership practices. Asia-Pacific Journal of Teacher Education, 43, 4-21. https://doi.org/10.1080/1359866X.2014.937393

Du Plessis, A., \& Sunde, E. (2017). The workplace experiences of beginning teachers in three countries: a message for initial teacher education from the field. Journal of Education for Teaching, 43(2). http://dx.doi.org/10.1080/02607476.2017.1286759

Fokkema, D. W., \& Ibsch, E. (2000). Knowledge and commitment: A problem-oriented approach to literary studies. Montreal: John Benjamins Publishers. https://doi.org/10.1075/upal.33

Freebody, P. (2003). Qualitative research in education: Interaction and practice. London: SAGE Publications. https://doi.org/10.4135/9781849209670

Fry, H., Ketteridge, S., \& Marshell, S. (2009). A handbook for teaching and learning in higher education: Enhancing academic practice. New York: Routledge.

Gadamer, H. G. (1975). Truth and method. New York: The Seabury Press.

Gadamer, H. G. (1976). Philosophical hermeneutics. Berkeley: University of California Press.

Gall, J. P., Gall, M. D., \& Borg, W. R. (1999). Applying educational research: A practical guide. New York: Longman.

Gay, G., \& Kirkland, K. N. (2003). Developing cultural critical consciousness and self-reflection in preservice teacher education. Theory into Practice, 42, 181-187. https://doi.org/10.1353/tip.2003.0029

Giroux, H. A. (1986). Radical pedagogy and the politics of student voice. Interchange, 17, 48-69. https://doi.org/10.1007/BF01811018

Gordon, B. M. (1985). Teaching teachers: "Nation at risk" and the issue of knowledge in teacher education. Urban Review, 17, 33-46. https://doi.org/10.1007/BF01141633

Grondin, J. (2002). Gadamer's basic understanding of understanding. In R. Dostal (Ed.), The Cambridge companion to Gadamer (pp. 36-51). Cambridge: Cambridge University Press. https://doi.org/10.1017/CCOL0521801931.003

Hammersley, M., Denzin, N., \& Lincoln, Y. (2006). Handbook of qualitative research. British Educational Research 
Journal, 32, 536-541. http://www.jstor.org/stable/30032683

Hardcastle, M. A., Usher, K., \& Holmes, C. (2006). Carspecken's five-stage critical qualitative research method: An application to nursing research. Qualitative Health Research, 16, 151-161. https://doi.org/10.1177/1049732305283998

Hargreaves, A. (1998). The emotional practice of teaching. Teaching and Teacher Education, 14, 835-854. https://doi.org/10.1016/S0742-051X(98)00025-0

Harman, G. (2005). Internationalization of Australian Higher Education: A Critical Review of Literature and Research. In P. Ninnes \& M. Hellstén (Eds.), Internationalizing Higher Education, (pp.119-140). Netherlands: Springer. https://doi.org/10.1007/1-4020-3784-8_7

Hood, S., \& Parker, L. (1994). Minority students informing the faculty: Implications for racial diversity and the future of teacher education. Journal of Teacher Education, 45, 164-171. https://doi.org/10.1177/0022487194045003002

Ingersoll, R. (2001a). The realities of out-of-field teaching. Educational leadership. May 2001, 42. Retrieved from http://www.EducationalLeadership/ingsoll.htm/full text. Accessed on 12 December 2002.

Ingersoll, R. (2001b). Rejoinder: Misunderstanding the problem of out-of-field teaching. Educational Researcher, 30, 21-22. Retrieved from http://ww.uga.edu/edu/columns/990503/campnews.html/full text

Ingersoll, R. (2002). Out of field teaching, educational inequality, and the organisation of schools: An exploratory analysis. Retrieved from http://www.ctpweb.org/full text. Accessed on 16 March 2004

Jones, S., Torres, V., \& Arminio, J. (2006). Negotiating the complexities of qualitative research in higher education. London: CRC Publisher.

Kaiser, G., Blömeke, S., König, J., Busse, A., Döhrmann, M., \& Hoth, J. (2016). Erratum to: Professional competencies of (prospective) mathematics teachers - cognitive versus situated approaches. Educational Studies in Mathematics. https://doi.org/10.1007/s10649-016-9724-5

Kezar, A. (2005). Redesigning for collaboration within higher education institutions: An exploration into the developmental process. Research in Higher Education, 46, 831-860. https://doi.org/10.1007/s11162-004-6227-5

Lave \& Wenger (1991). Situated Learning: Legitimate Peripheral Participation. Cambridge: Cambridge University Press.

Ladson-Billings, G. (1999). Preparing teachers for diversity. In L. Darling-Hammond \& G. Sykes (Eds.), Teaching as the learning profession (pp. 86-123). San Francisco: Jossey-Bass.

Laschke, C., \& Blömeke, S. (2016). Measurement of job motivation in TEDS-M: Testing for invariance across countries and cultures. Large-scale Assessments in Education, 4, 1-17. https://doi.org/10.1186/s40536-016-0031-5

Loughran, J. (2013). Pedagogy: Making sense of the complex relationship between teaching and learning. Curriculum Inquiry, 43, 118-141. https://doi.org/10.1111/curi.12003

Luke, A., Luke, C., \& Mayer, D. (2000). Redesigning teacher education. Teaching Education, 11(1), 5-11. https://doi.org/10.1080/10476210050020318

McConney, A., \& Price, A. (2009). Teaching Out-of-Field in Western Australia. Australian Journal of Teacher Education, 34(6). https://doi.org/10.14221/ajte.2009v34n6.6

McIntyre, D., Pedder, D., \& Rudduck, J. (2005). Pupil voice: Comfortable and uncomfortable learnings for teachers. Research in Higher Education, 20, 149-168. https://doi.org/10.1080/02671520500077970

McMillan, J. H., \& Schumacher, S. (2001). Research in education: A conceptual introduction. New York: Longman.

Mertens, D. M., \& McLaughlin, J. A. (2004). Research and evaluation methods in special education. Thousand Oaks: Corwin Press Inc. https://doi.org/10.4135/9781412985666

Moran, D., \& Mooney, T. (2002). The phenomenology reader. London: Routledge.

O'Cathain, A., \& Thomas, K. (2006). Combining qualitative and quantitative methods. In C. Pope \& N. Mays (Eds.), Qualitative research in health care. Toronto: Blackwell Publishing. https://doi.org/10.1002/9780470750841.ch9

Oliver-Hoyo, M., \& Allen, D. (2006). The use of triangulation methods in qualitative educational research. Journal of Counseling Psychology, 35, $42-47$. 
Patton, M. (2002). Qualitative research and evaluation methods (3rd ed.). Thousand Oaks: Sage Publications.

Peräkylä, A. (2004). Reliability and validity in research based on naturally occurring social interaction. In D. Silverman (Ed.), Qualitative research: Theory and practice, (pp. 283-304, Chapter 215). London: SAGE Publications.

Polkinghorne, D. E. (2005). Language and meaning: Data collection in qualitative research. Journal of Counseling Psychology, 52, 137-145. https://doi.org/10.1037/0022-0167.52.2.137

Ramsden, P. (2003). Learning to teach in higher education (2nd ed.). London: RoutledgeFalmer.

Reisetter, M., Korcuska, J. S., Yexley, M., Bonds, D., Nikels, H., \& McHenry, W. (2004). Counselor educators and qualitative research: Affirming a research identity. Counselor Education and Supervision, 44, 2-16. https://doi.org/10.1002/j.1556-6978.2004.tb01856.x

Rizvi, F., \& Lingard, B. (2010). Golobalizing education policy. New York: Routledge.

Seidman, I. (1998). Interviewing as qualitative research: A guide for researchers in education and the social sciences. New York: Teachers College Press.

Sleeter, C. E. (2001). Epistemological diversity in research on preservice teacher preparation for historically underserved children. Review of Research in Education, 25, 209-250. http://journals.sagepub.com/doi/pdf/10.3102/0091732X025001209

Smyth, J. (2013). Losing our way? Challenging the direction of teacher education in Australia by reframing it around the socially just school. Asia-Pacific Journal of Teacher Education, 41, 111-122. https://doi.org/10.1080/1359866X.2012.753990

Speziale, H. S., \& Carpenter, D. R. (2007). Qualitative research in nursing: Advancing the humanistic imperative. New York: Wolters Kluwer Health Publishers.

Swidler, S. A. (2000). Contextual conflicts in educators? Personal experience narratives. International Journal of Qualitative Studies in Education, 13, 553-568. https://doi.org/10.1080/09518390050156468

Teacher Education Ministerial Advisory Group (TEMAG). (2014). Action now: Classroom ready teachers. Retrieved from http://www.studentsfirst.gov.au/teacher-education-ministerial-advisory-group.

Van Manen, M. (1990). Researching lived experience: Human science for an action sensitive pedagogy. New York: The State University of New York Press.

Vessey, D. (2007). Gadamer's hermeneutic contribution to a theory of time-consciousness. Indo-Pacific Journal of Phenomenology, 7, 1-7. https://doi.org/10.1080/20797222.2007.11433947

Vygotsky, L. (1978). Mind in society: The development of higher psychological processes. United States of America: Harvard University Press.

Wengraf, T. (2001). Qualitative research interviewing. London: Sage Publication. https://doi.org/10.4135/9781849209717

Zepeda, S. J. (2006). High stakes supervision: We must do more. International Journal of Leadership in Education, 9 , 61-73. https://doi.org/10.1080/13603120500448154

\section{Notes}

Note 1. Pseudonym 